Sun Myung Lyu

\title{
Righteousness in the Book of Proverbs
}

[Das Konzept der Rechtschaffenheit in den Sprüchen Salomos.]

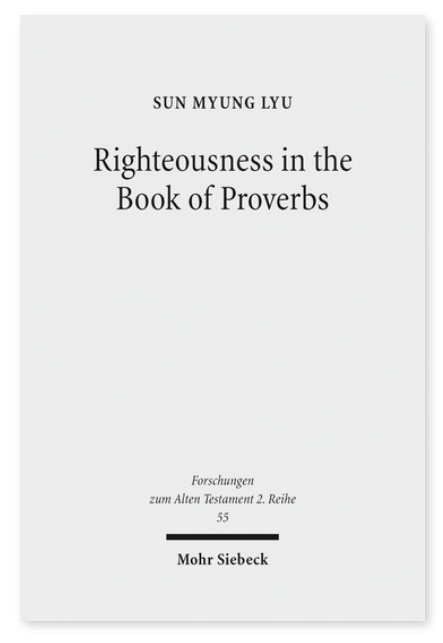

2012. XI, 154 Seiten. FAT II 55

ISBN 978-3-16-152347-2

DOI 10.1628/978-3-16-152347-2

eBook PDF 59,00€

ISBN 978-3-16-149872-5

fadengeheftete Broschur 59,00€
Veröffentlicht auf Englisch.

Sun Myung Lyu verbindet Erkenntnisse aus einer Ethik des Charakters mit der theologischen Debatte um soziale

Gerechtigkeit in der Bibel und wendet diese auf seine Untersuchung des Konzepts der Rechtschaffenheit in den Sprüchen Salomos an. Er zeigt, dass die Sprüche sehr deutlich einen idealen Menschen als Paradigma des moralisch richtigen Lebens charakterisieren. Den idealen Menschen zeichnet vor allem Rechtschaffenheit aus, und diese Eigenschaft umfasst und transzendiert einzelne Tugenden und bestimmte moralisch richtige Handlungen.

Der Autor vergleicht zunächst die Sprüche mit den Psalmen und antiken ägyptischen Weisheitstexten und stellt im Ergebnis fest, dass die Sprüche - trotz zahlreicher Gemeinsamkeiten und Parallelen - insofern ein eigenes Konzept herausbilden, als sie die Charakterbildung und die Internalisierung von Tugenden als Grundlage des moralischen Handelns im Allgemeinen und der Rechtschaffenheit im Besonderen in den Mittelpunkt stellen.

Sun Myung Lyu Born 1963; currently assistant professor at Baekseok University in South Korea.

Jetzt bestellen:

https://mohrsiebeck.com/buch/righteousness-in-the-book-of-proverbs-9783161523472?no_cache=1

order@mohrsiebeck.com

Telefon: +49 (0)7071-923-17

Telefax: $+49(0) 7071-51104$ 